\title{
MESA 1: RELATORIA
}

VALESCA AMES ${ }^{1}$

UFRGS

Entre os dias 9 e 10 de novembro de 2015, ocorreu, no auditório do Instituto Latino-Americano de Estudos Avançados (ILEA), da Universidade Federal do Rio Grande do Sul (UFRGS), o seminário "Ações Afirmativas no PPGAS/UFRGS: diálogos com experiências de inclusão e permanência de estudantes indígenas, negros e pessoas com deficiência na universidade brasileira". O seminário foi organizado pelo Programa de Pós-Graduação em Antropologia Social desta Universidade.

Para tratar sobre as experiências na pós-graduação brasileira em Antropologia, tema do primeiro dia de encontro, a mesa de abertura contou com a presença de importantes pesquisadores, estudantes e intelectuais negros e indígenas: Antonio Carlos de Souza Lima, Francisco Apurinã, Anderson da Costa Pereira, Marcela Coelho de Souza e Ana Elisa Freitas. Cada participante teve em torno de vinte e cinco minutos para desenvolver sua fala, com posteriores cinquenta minutos de debate com o público. Contou-se, também, com a presença de Ailton Krenak, que fez algumas considerações ao final da exposição da mesa, coordenada pelo professor Sergio Baptista da Silva.

A fala de abertura foi realizada pela professora e coordenadora do Programa de Pós-Graduação em Antropologia Social da Universidade Federal do Rio Grande do Sul (PPGAS/UFRGS), Patrice Schuch. Patrice primeiramente agradeceu a participação de todos e, especialmente,

\footnotetext{
${ }^{1}$ Graduada em Ciências Sociais pela Universidade Federal de Santa Maria (UFSM). Mestre pelo Programa de Pós-Graduação em Sociologia da Universidade Federal do Rio Grande do Sul (PPGS/UFRGS), onde atualmente cursa o Doutorado. E-mail: valesca.ames@gmail.com .
} 
daqueles que vivenciam e lutam pelo incentivo das experiências de ações afirmativas na pós-graduação. Nesse sentido, mencionou o "Grupo de Trabalho de Ações Afirmativas" coordenado pelo professor Sergio Baptista da Silva, cujo esforço resultou na organização do seminário. $O$ que interessa discutir, segundo Patrice, são os desafios colocados para a pós-graduação e para a universidade, fomentando redes de colaboração para que eles sejam superados. Entre os desafios, mencionou a impossibilidade de financiamento de pessoas que não sejam professores universitários - dificuldade vivenciada durante a organização do seminário. Patrice agradeceu novamente e disse ser uma felicidade estar participando do encontro. Por fim, citou um texto produzido por Ailton Krenak para pensar sobre o papel da Antropologia, que, em sua versão clássica e hegemônica, elegeu as comunidades indígenas como objetos de pesquisa, mas que, agora, é desafiada a se transformar e dialogar com essas mesmas comunidades.

Em seguida, Sergio Baptista passou a palavra para o professor Antonio Carlos de Souza Lima. Antonio Carlos é professor do Programa de Pós-Graduação em Antropologia Social da Universidade Federal do Rio de Janeiro (UFRJ), tendo experiência na área da Antropologia do Estado (indigenismo, política indigenista, povos indígenas e universidade). É também presidente da Associação Brasileira de Antropologia (ABA). Antonio Carlos cumprimentou a mesa e agradeceu o convite para a participação no seminário. Disse ser uma satisfação tratar sobre um tema que dividiu opiniões na Antropologia brasileira. Para exemplificar, citou a criação de uma comissão de relações étnico-raciais na ABA, em 2002, que serviria para protegê-la de discussões sobre ações afirmativas que estavam despontando naquele momento. Disse ser uma felicidade participar de um encontro sobre um tema que "veio para ficar", e que vai transformar a Antropologia e a vida universitária nos próximos anos.

Francisco Apurinã falou em seguida. Francisco é indígena, doutorando em Antropologia Social na Universidade de Brasília (UnB) e originário do sul do Amazonas. Agradeceu aos organizadores do evento, por ser este relevante tanto para a academia quanto para os povos indígenas. Contou sobre uma conversa com sua comunidade, após a seleção para ingresso no doutorado, e disse que eles não desejavam que ele fosse para a universidade, mas que gostariam que ele "estudasse os 
brancos, pois estavam cansados de serem pesquisados". Por outro lado, pensa que, mais do que um "estudo dos brancos", é uma troca de conhecimento, já que muitos pesquisadores só conhecem indígenas por meio de livros e documentários, tendo a universidade muito a ganhar com esse ingresso.

Em seguida, falou Larisse Pontes Gomes, negra, mestranda em Antropologia Social na Universidade Federal de Santa Catarina (UFSC). Larisse cumprimentou a mesa e agradeceu o convite para participar do evento. Falou da importância de se estabelecer um diálogo e construção de conhecimentos "a partir de outros lugares".

$\mathrm{Na}$ sequencia, Sergio Baptista tomou a palavra para falar sobre a organização, estrutura e objetivos do seminário. Disse que a "Comissão de Ações Afirmativas do PPGAS/UFRGS", que coordena, propôs o seminário para a construção e consolidação das Ações Afirmativas na pós-graduação, por meio de diálogos sobre o ingresso e permanência de estudantes negros, indígenas e com deficiência. Assim, a estrutura do seminário comportaria dois momentos: o primeiro composto por diálogos de experiências em universidades brasileiras, e o segundo por experiências na Universidade Federal do Rio Grande do Sul (nos Programas de Pós-Graduação em História e Educação). As discussões seriam realizadas em mesas redondas, das quais seriam produzidas relatorias. O objetivo dos debates seria a construção de uma política que vise o ingresso e, principalmente, a permanência dos estudantes na universidade, por meio da criação de bases epistemológicas, sociais e culturais bem como critérios e mecanismos práticos para alcançar a inclusão e formação desses estudantes no Programa de Pós-Graduação em Antropologia Social.

A seguir, Sergio mencionou os participantes de cada uma das mesas. A primeira seria constituída por Antonio Carlos de Souza Lima, Anderson Lucas da Costa Pereira, Marcela Coelho de Souza, Francisco Apurinã, Ana Elisa Freitas e Ailton Krenak. A segunda por Antonella Tassinari, Larisse Pontes, Willian Luiz da Conceição, Raimundo Nonato Pereira da Silva, Roslilene Fonseca Pereira e Rosani de Fátima Fernandes. A terceira mesa, do segundo dia de seminário, seria composta por estudantes e professores da UFRGS que passaram pela experiência de ingresso de estudantes cotistas em seus cursos de pós-graduação. Sergio 
reiterou os agradecimentos e apontou como expectativas das apresentações uma avaliação sobre os processos seletivos, os mecanismos de acolhimento dos selecionados e medidas sobre a permanência e acompanhamento desses estudantes (tutorias, bolsas, cursos de idiomas). Dando início à mesa, convidou o professor Antonio Carlos de Souza Lima para expor suas considerações a respeito do tema.

Antonio Carlos de Souza Lima agradeceu novamente o convite para participação no seminário e relembrou o processo de criação das Ações Afirmativas no curso de Pós-Graduação em Antropologia Social da UFRJ, com o qual não teve envolvimento direto, sendo iniciativa do corpo discente do programa. Disse que muitos impasses e dificuldades envolvidas com o ingresso dos estudantes cotistas ainda continuam ocorrendo e "estão longe de serem sanados".

Antonio Carlos falou, então, "de onde ele vem", e explanou sobre a sua participação e experiência com o "Programa Internacional de Bolsas" para estudantes indígenas e negros, criado e financiado pela Fundação Ford. Esse programa permitiu que os primeiros indígenas e negros acessassem a pós-graduação no Brasil. A ideia da Fundação Ford seria a de promover a mudança social a partir da formação de novas lideranças indígenas e negras. No entanto, as bolsas não eram totalmente preenchidas porque não existiam indígenas e negros formados nos cursos de graduação nas universidades brasileiras. Criou-se, assim, o programa "Caminhos para Educação Superior", que se prolongou por dez anos. Segundo Antonio Carlos, percebia-se que o problema de acesso dos estudantes indígenas à pós-graduação se reproduzia na graduação: as lacunas formativas no ensino médio, tendo em vista que a política para educação indígena era voltada para o ensino fundamental. Esse problema foi, em parte, sanado com as políticas de formação de professores indígenas para atuarem nas aldeias.

Segundo Antonio Carlos, o "Programa Internacional de Bolsas" oferecia muitos benefícios aos estudantes indígenas, como cursos de idiomas e um período de preparação para ingresso na pós-graduação que se estendia por um ano. E não partia de um princípio de acesso diferenciado. Por outro lado, as Ações Afirmativas para a pós-graduação no Brasil permitem um acesso diferenciado, porém, não temos uma bolsa e um tempo diferenciado, nem tampouco estruturas adequadas de 
acolhimento aos estudantes cotistas. As redes informais de apoio (como as relações "orientador-orientando") acabariam fazendo a diferença nesses casos.

Antonio Carlos comentou, ainda, que a presença de estudantes negros e indígenas na pós-graduação coloca muitas questões sobre as quais é preciso pensar. Por exemplo, a importância de se estudar a história da Antropologia brasileira enquanto um campo de poder/saber; a questão de saber se os autores e as metodologias estudadas "fazem sentido" para os indígenas; a importância de se discutir a noção de "raça". Por fim, coloca que os ambientes universitários ainda são "inóspitos" para os estudantes indígenas.

Na sequência, Sérgio leu a fala de Anderson da Costa Pereira, que enviou sua intervenção por escrito. Anderson é negro, mestrando em Antropologia Social no Museu Nacional/UFRJ e desenvolve pesquisa na área da Antropologia das Populações Afro-Brasileiras. Anderson iniciou pedindo desculpas aos presentes e aos movimentos sociais, por estar tratando de um assunto tão sério de forma prolixa e sem a linguagem política adequada, mas espera que essa escolha seja justificada ao longo de sua fala.

Afirmou que, ao tratar do tema das Ações Afirmativas, sente um "embrulho" e uma tristeza, pois lembra o racismo e suas variantes disfarçadas. Passa, então, a falar da sua experiência enquanto estudante negro cotista do Programa de Pós-Graduação em Antropologia do Museu Nacional. Mas também "do Anderson de alguns anos atrás", de 1997, ano em que começaria a cursar o ensino médio. Naquela época, quando ainda morava em Belém, procurava por uma boa escola. Porém, para ingressar nesta, era preciso ter relações pessoais com a diretoria ou passar em uma prova seletiva muito disputada. Depois de muito esforço, Anderson relata que conseguiu se classificar e ingressar na escola.

Em 1999, terminou o ensino médio e tentou pela primeira vez o vestibular, porém, sem sucesso. Nos anos subsequentes, tentou novamente, em 2000, 2001, 2002... No final deste período, viu propagandas de cursinhos pré-vestibulares na televisão, e se informou sobre os valores, porém, seus pais não conseguiriam sequer pagar a taxa de matrícula. Decidiu, então, ingressar em uma universidade particular, onde cursou Direito por seis meses, quando foi barrado por falta de 
pagamento das mensalidades. Em 2005, um tio lhe perguntou: "por que você não tenta o PROUNI?". Foi atrás de mais informações, fez sua inscrição e, em 2006, ingressou no curso de Administração, no Centro Universitário do Estado do Pará.

No primeiro dia na universidade, foi barrado pelo porteiro. Na roda de apresentações em sala de aula, percebeu que era o único negro da turma. Quando se apresentou, ouviu comentários racistas sussurrados por alguns colegas. Disse que foram os primeiros meses mais sofridos de sua vida, pois não conseguia socializar.

Em 2010, ingressou no curso de Antropologia, na Universidade Federal do Oeste do Pará. Em 2014, foi pela primeira vez para a cidade do Rio de Janeiro, tentar ingressar no mestrado em Antropologia Social, no Museu Nacional. Contou do racismo vivenciado na cidade, em diferentes situações, e das dificuldades financeiras. Conseguiu a classificação, quando sentiu "seu corpo sendo carregado para todos os anos vividos anteriormente". Na universidade, sentiu novamente o racismo, quando o porteiro pedia cotidianamente que mostrasse seu crachá, o que não era demandado dos demais alunos. Finalizando sua fala, Anderson citou a letra da música de Dona Ivone Lara, chamada "sorriso negro".

Em seguida, falou a professora Marcela Coelho de Souza. Marcela é professora do Departamento de Antropologia da Universidade de Brasília (UnB). Tem experiência na área de Antropologia, com ênfase em Etnologia Indígena. Agradeceu o convite para participação no seminário e disse que se engajou nesse tema há pouco tempo, sendo que a implantação das Ações Afirmativas no Programa de Pós-Graduação em Antropologia Social da UnB foi iniciativa dos alunos. Em 2013, começaram a discutir a política, implementada na seleção de 2014. Disse que, assim que a discussão foi posta, um dos problemas apontados seria a criação de uma política de acolhimento para os estudantes que ingressariam. Percebeu-se, ao longo do debate, que a política só poderia ser construída na prática, por meio dos problemas que seriam colocados. Começaram, então, pelo ingresso.

Segundo Marcela, a política de ingresso é diferenciada, com reserva de vagas para optantes negros na seleção universal e uma seleção diferenciada para os indígenas. A seleção também é diferenciada para o mestrado e para o doutorado. A seleção para optantes negros, no 
mestrado, inclui três fases: exame de currículo, ensaio bibliográfico e entrevista. No doutorado, as fases contemplam análise de projeto, prova e entrevista. Quanto à seleção para os optantes indígenas, afirma que é exigido um documento em que o candidato recupere a sua trajetória de vida e suas expectativas para o curso, em termos de projeto. A nota de corte foi mantida para os cotistas. A prova de línguas deixou de ser eliminatória para esses candidatos. Foi reservada uma vaga para ingresso de indígenas no mestrado e uma vaga para o doutorado.

Com relação ao ingresso no curso de mestrado, Marcela afirma que, em 2014, dos 62 aprovados na primeira fase, 10 eram optantes; na segunda etapa, dos 22 aprovados, quatro eram optantes; na terceira, dos 15 aprovados, dois eram optantes. Ao término do processo seletivo, verificou-se que os estudantes que haviam optado pelas vagas diferenciadas acabaram ingressando pelas universais, devido à alta nota alcançada na classificação final. Na seleção do mestrado de 2015 , houve apenas um ingresso em vaga reservada. O doutorado teria uma configuração similar. Após esses resultados, afirmou que houve uma discussão sobre os mecanismos que impediriam o ingresso de maior número de estudantes cotistas, visto que as vagas reservadas não estavam sendo totalmente preenchidas. Sugere que seja a intervenção de ideais de mérito no objetivo das políticas de Ações Afirmativas.

Ainda, Marcela retoma as intenções iniciais da implementação da política de Ações Afirmativas para ingressantes indígenas, que era a de formar acadêmicos indígenas que haviam realizado seus cursos em graduações diferenciadas, trazendo, assim, uma diversidade de trajetórias, de formações e de conhecimentos para a universidade.

Quanto aos desafios enfrentados, menciona que o "medo do acolhimento" está sendo resolvido. Os estudantes indígenas estão morando em casas de estudantes pertencentes à universidade, uma espécie de resolução transitória para o problema da moradia. A solução a longo prazo é a extensão de bolsas de permanência para estudantes indígenas na pós-graduação, sendo esta cumulativa com outras bolsas uma política que já existe para estudantes indígenas de cursos de graduação.

Finalizando, Marcela aponta que um desafio a ser ainda enfrentado é a adaptação dos professores às questões que são trazidas por estes 
novos alunos, que carregam "coletivos" e vivências consigo, e também "outro olhar" sobre a Antropologia.

Sergio passou a palavra para Francisco Apurinã. Francisco resgatou a fala de Anderson, dizendo que este retratou uma realidade também enfrentada por ele e por sua comunidade. Narrou, então, o episódio de seu nascimento. Disse vir de uma família composta por três filhas mulheres, e que seu pai, cacique da aldeia, esperava a chegada de um homem. Sua mãe estava há oito anos sem engravidar e seu pai começou a se preocupar. Seu avô, pajé, disse, então, a seu pai: "leve sua mulher para a terra firme, encontre uma fruta lá, e a dê a sua mulher". Assim teria sido seu nascimento.

Sobre o seu ingresso no doutorado em Antropologia Social na Universidade de Brasília, Francisco relatou que "teve que ler todos os clássicos" e que se sentiu limitado para expor aquilo que conhece ou acredita. Disse que na cultura do seu povo, até os dez anos deve-se saber caçar, fazer roçado e pescar. Aos doze anos "deu os primeiros passos no mundo da escrita". Veio, então, para a cidade estudar e conhecer esse "novo universo". Os primeiros passos teriam sido mais difíceis, pois era o único indígena, muitas vezes visto como sinônimo de "coisas ruins". No Dia do Índio, não frequentava a escola, pois todos se reportavam a ele. Nesses momentos se perguntava: "como meu pai me deixou vir ao mundo para sofrer?". Disse que não conseguia entender.

Segundo Francisco, em sua adolescência começou a sentir vergonha de ser indígena, e desejava "desaprender" o que sabia sobre sua aldeia, sua comunidade. Depois da graduação, sentiu vontade de reaprender novamente a língua indígena, quando passou oito meses em sua comunidade.

Em 2010, ingressou no mestrado em Desenvolvimento Sustentável, onde conheceu um "universo teórico" composto por temas que ele já conhecia por meio da sua vivência na comunidade. Disse que, no início, não conseguia entender o sentido do termo "desenvolvimento sustentável", mesmo que já tivesse o estudado muitas vezes. Falou, então, com seu pai, que lhe disse que "sustentabilidade" era a experiência de "ir à mata e não pegar todas as frutas, porque delas também precisam outros animais e plantas". A partir dessa explicação, o termo fez mais sentido para ele. 
Francisco afirmou também que a Antropologia o fez repensar muitas coisas, e quis estudá-la para entender por que ela seria mais requisitada para trabalhar com os povos indígenas. No início, não conseguia entender por que deveria ler Frazer e Morgan, não entendia no que eles se relacionavam com os povos indígenas. Disse que a disciplina ainda está despreparada para trabalhar com as comunidades indígenas. Igualmente, que outros profissionais estão despreparados, como os agrônomos, que desejam "ensinar as comunidades a plantar", desconsiderando seus saberes, suas crenças e práticas.

Em seguida, a palavra passou novamente para Marcela, que pediu para concluir sua fala, complementando o que havia sido dito por Francisco. Ela comentou sobre a sua experiência enquanto professora de alunos indígenas. Disse que, quando ministrou a disciplina de "Clássicos", percebeu que ela só fazia sentido "para nós". Também criticou aquelas posições que buscam referendar os discursos dos indígenas segundo abordagens teóricas definidas. Disse que a diversidade deve estar no ingresso e na formação dessas pessoas.

A seguir, Ana Elisa Freitas fez sua intervenção. Ana Elisa é professora da Universidade Federal do Paraná e atua nas áreas de Antropologia e Educação, com ênfase em territórios indígenas, interculturalidade e políticas públicas. Inicialmente, agradeceu o convite para participação no seminário. Afirmou que a questão chave a se pensar a respeito do ingresso de estudantes negros e indígenas nas universidades é o reconhecimento da diferença. Chamou a atenção para o reconhecimento das epistemologias indígenas e campos fenomenológicos que essas alteridades nos abrem para pensar a universidade. Nesse sentido, resgatou o mérito da língua indígena, suas perspectivas de desenvolvimento, ecologia, arte e antropologia.

Ana Elisa apresentou, então, a sua experiência no mestrado em Desenvolvimento Territorial Sustentável, na Universidade Federal do Paraná (UFPR), e suas expectativas quanto ao que denominou "pré-pós", um potencial programa de preparação para estudantes negros e indígenas, com um ano de duração, anterior ao ingresso destes nos cursos de pós-graduação. Apontou, ainda, sua experiência na graduação, com os Programas de Educação Territorial Indígena (PET). 
Segundo Elisa, um tema central para pensar a presença indígena nas universidades é a mobilidade desses estudantes, para que se mantenham os vínculos com suas comunidades. Por isso, afirmou ser necessária uma bolsa-mobilidade. Além disso, é preciso pensar na questão da moradia, das bolsas e no acompanhamento dos egressos. Ana Elisa sugeriu, também, que se criem cursos à distância para indígenas, visto que muitos deles ficam um tempo longe da universidade entre seus cursos de graduação e pós-graduação.

Sergio convida, então, Ailton Krenak para compor a mesa. Ailton Krenak é um líder e intelectual indígena. Ailton agradeceu a acolhida e cumprimentou a mesa e os participantes do seminário. Afirmou que a universidade, por muito tempo, ficou restrita aos filhos da "Casa Grande", e que apenas recentemente tem aberto suas portas para receber os povos menos favorecidos. Disse que existem, agora, as Ações Afirmativas porque temos um histórico de desrespeito e discriminação com aqueles que não nasceram na "Casa Grande". Afirmou, ainda, que quem nasce em uma aldeia, em um quilombo ou em uma favela já nasce com seu destino mais ou menos indicado. Além disso, colocou que, se reproduzirmos o "mundo dos brancos", conseguiremos trabalhar, obter bens, desenvolver nossas profissões com sucesso, seremos "bem-sucedidos", o que é muito diferente de "bem-viver".

Após a fala de Ailton, Sergio abriu espaço para os questionamentos dirigidos para a mesa.

A primeira a se manifestar foi Patrice Schuch. Patrice agradeceu as falas e disse que foram muito interessantes. Perguntou sobre os debates a respeito da implementação das Ações Afirmativas dentro dos programas de pós-graduação e se existiram mecanismos contínuos de reflexão no interior dos mesmos. Ainda, questionou se existiram mecanismos de interação institucionais na relação entre os discentes e as políticas de Ações Afirmativas.

A seguir, falou Danilo Braga, estudante Kaingang. Danilo comentou sobre a sua trajetória e falou que foi difícil sair da aldeia e ingressar na universidade.

Outro membro da plateia pediu a palavra e disse que gostaria de saber mais sobre a "avaliação solidária" mencionada por Marcela, e 
também sobre o "pré-pós" comentado por Elisa. Igualmente, gostaria de saber como conseguiram financiamento para as ideias apresentadas.

Sergio passou então novamente a palavra para a mesa.

A primeira a se manifestar foi Elisa. Elisa afirmou que o principal desafio a ser enfrentado no ingresso de estudantes cotistas na universidade são as estruturas administrativas coloniais desta. Quanto aos projetos citados, disse que estão desenhados, mas que ainda faltam os recursos financeiros.

Antonio Carlos colocou que a discussão sobre as Ações Afirmativas começou por iniciativa dos alunos do programa, foi levada para o corpo docente, onde "gerou certa celeuma" e parou durante um período. A discussão foi precedida pelo fato de que um indígena se inscreveu na seleção do Museu Nacional, e se deliberou naquele momento de que a seleção seria diferenciada. No entanto, afirmou que o grande desafio era a permanência. Igualmente, comentou que há uma reflexão sobre cada seleção realizada. Porém, não existe uma reflexão sobre a presença indígena ou sobre a estrutura do curso. Disse, ainda, que os recursos financeiros (bolsas) não deveriam ser diferenciados apenas para os indígenas, mas também para os negros. Por fim, Antonio reiterou a importância de se conhecer amplamente o que a UFRGS faz no âmbito das Ações Afirmativas.

Em seguida, Marcela se manifestou. Disse que a discussão sobre as Ações Afirmativas na UnB foi iniciativa dos discentes. Hoje, a "celeuma" inicial se traduziria em certo descomprometimento. Sobre a avaliação solidária, afirmou que foram soluções informais e locais. Quanto à moradia, disse ser preciso discutir diferentes formatos, pois a moradia conjunta pode não ser uma boa opção. No que diz respeito ao "pré-pós", afirmou que se deve levar em conta que ele não substitui a preparação que deve ser realizada internamente nos programas.

Antonio Carlos pediu a palavra novamente para falar sobre a "educação à distância" colocada por Elisa. Antonio Carlos afirmou que o problema é o acesso à internet para os povos indígenas, e que também é pessimista em relação às possibilidades de aprendizagem à distância.

Francisco colocou que veio de um "mundo da partilha", e que esse foi seu primeiro "choque cultural" ao morar em Brasília. Disse, ainda, que é preciso inicialmente que os estudantes negros e indígenas ingressem 
nos programas de pós-graduação, para saber quais desafios devem ser enfrentados. Com relação à avaliação solidária, comentou que a iniciativa partiu dos alunos que tinham condições de realizar as leituras em línguas estrangeiras e que se disponibilizaram a auxiliar os demais.

Elisa pede novamente a palavra para falar sobre a educação à distância. Comentou que a ideia surgiu a partir de uma interlocução com um estudante indígena, onde ela e este estudante trocaram informações por um período de um ano após a conclusão de seu curso de graduação, via e-mail.

Por fim, Sergio agradeceu a participação e o compartilhamento das experiências dos membros da mesa. Também agradeceu a Comissão e a equipe de organização.

Recebido em: 14/11/2015* Aprovado em: 14/12/2015 * Publicado em: 31/12/2015 